http://artnodes.uoc.edu

\title{
Arqueología de la interactividad: el libro móvil y pop-up como antecedente de los videojuegos
}

\author{
Alfonso Cuadrado Alvarado \\ Universidad Rey Juan Carlos Madrid \\ Fecha de presentación: febrero de 2018 \\ Fecha de aceptación: marzo de 2018 \\ Fecha de publicación: junio de 2018
}

\section{Cita recomendada}

Cuadrado, Alfonso. 2018. «Arqueología de la interactividad: el libro móvil y pop-up como antecedente de los videojuegos». En Pau Alsina, Ana Rodríguez y Vanina Y. Hofman (coords.). «Arqueología de los medios». Artnodes. N. ${ }^{0} 21: 119-126$. UOC [Fecha de consulta: dd/mm/ aa]. http://dx.doi.org/10.7238/a.v0i21.3183.

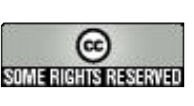

Este artículo está sujeto -si no se indica lo contrario- a una licencia de Reconocimiento 3.0 España de Creative Commons. Puede copiarlos, distribuirlos, comunicarlos públicamente, hacer obras derivadas y usos comerciales siempre que reconozca los créditos de las obras (autoría, nombre de la revista, institución editora) de la manera especificada por los autores o por la revista. La licencia completa se puede consultar en http://creativecommons.org/licenses/by/3.0/es/deed.es.
}

\section{Resumen}

Este trabajo se centra en un terreno escasamente explorado: los antecedentes culturales del videojuego. Más allá de las referencias a los juegos tradicionales, deportivos o de mesa, las tecnologías digitales e incluso mecánicas que se muestran como antecesores directos (computadoras o pinballs) del videojuego responden a una larga tradición que hunde sus raíces en los espectáculos populares de los siglos XVIII y xIx. Su nacimiento como medio con gran capacidad de hibridación cultural tiene un paralelismo con el del libro móvil y desplegable. El libro tradicional evoluciona como soporte para sintetizar, en una única experiencia, las nuevas formas de entretenimiento como el panorama, las fantasmagorías, los espectáculos de marionetas y autómatas, el peep show, los dioramas y las ilusiones ópticas de zootropos o linternas mágicas. Mediante una técnica nueva como es la ingeniería de papel, que emula la mecánica 


\title{
artnodes
}

http://artnodes.uoc.edu

Arqueología de la interactividad...

del autómata, rompe la inmovilidad de la imagen permitiendo las primeras animaciones de personajes asociadas a un relato y la construcción de un espacio tridimensional explorable. El lector interviene por primera vez en el proceso de la narración, interactuando con las partes móviles y componiendo un mundo de ficción sobre la base de su actividad y de las nuevas relaciones entre texto e imagen, distintas a las que mantenían en el libro ilustrado. Se crea por primera vez un artefacto lúdico distinto al juguete tradicional, en un proceso muy similar al que dará lugar al juego electrónico cien años después. La evolución de ambos soportes conlleva soluciones de desarrollo similares en cuanto a técnicas de animación, creación del punto de vista 0 a la relación entre la narración y la interacción. El artículo revela, como conclusión, el permanente vínculo de los videojuegos con la herencia lúdica del siglo xIx y cómo este influjo vuelve al espectáculo de la mano de la realidad virtual.

\section{Palabras clave}

videojuegos, libros móviles, interactividad, arqueología de los medios

\section{Archaeology of interactivity: the pop-up book as the forerunner of video games}

\begin{abstract}
This paper focuses on a scarcely explored field: the cultural background of the video game. Notwithstanding the relationship to traditional games, sports and board games, digital and even mechanical technologies which are shown as direct forerunners (computers or pinball games), the video game responds to a long tradition that has its roots in popular 18th-and 19th-century performances. Its birth as a medium with a great capacity for cultural hybridisation has a parallel with the pop-up book. The traditional book developed as a means to combine new forms of entertainment such as the panorama, the phantasmagoria, puppet shows and automatons, the peep show, dioramas and the optical illusions of zoetropes or magic lanterns. The new technique of paper engineering, which emulated the mechanics of the automaton, broke the immobility of the image and allowed for the first animations of characters associated with a story and the construction of a three-dimensional explorable space. For the first time, the reader was involved in the narrative process, interacting with the moving parts and composing a world of fiction based on their activity and on the new relationships between text and image, unlike those in illustrated books. Also for the first time, it created a fun artefact different from the traditional toy, in a process very similar to the one that would give rise to electronic games one hundred years later. The evolution of both resources led to similar development solutions in terms of animation techniques, creation of the point of view and the relationship between narration and interaction. This paper ultimately reveals the permanent link between video games and the legacy of 19th-century entertainment, and how this influence feeds into the idea of performance via virtual reality.
\end{abstract}

\section{Keywords}

video games, movable books, interactivity, media archaeology 


\section{artnodes}

\section{Introducción}

Los videojuegos, a diferencia del cine o la televisión, no han merecido la atención por parte de la arqueología de los medios que cabría esperar por su repercusión industrial y cultural. Su capacidad de hibridación y remediación (Bolter y Grusin 1998) les permite beber de todo tipo de fuentes: literatura, teatro, cine, comic, deportes, juegos de mesa, juguetes, simulaciones, etc. Consideramos que constituyen un nicho de investigación que permanece casi intacto en lo que se refiere a la arqueología de los medios, máxime cuando son muchas las influencias que se pueden rastrear. Los videojuegos no son exclusivamente el fruto del desarrollo de las tecnologías de la computación, una invención sin rastro en la historia mediática (Huhtamo 2007); son los directos herederos de una larga tradición ficcional que hunde sus raíces en todo tipo de espectáculos populares desde el siglo xVIII. Es en este territorio donde se enmarca el presente trabajo. La aproximación que presentamos no nace inspirada por su naturaleza tecnológica, lo que resultaría más evidente, ni por otear las conexiones con espectáculos interactivos con cierta similitud operativa o por las formas del juego anteriores al videojuego. El nexo que se construye nace de la mirada hacia los procesos que tienen lugar para impulsar la evolución de los soportes culturales, en este caso el libro, como génesis posteriores de los medios.

Entendemos que la tradicional linealidad histórica que busca presentar una secuencia de pasos o hitos en el alumbramiento de los medios no corresponde con una realidad plagada de cruces e influencias trasversales. En palabras de Zielinski: «The history of the media is not the product of a predictable and necessary advance from primitive to complex apparatus. [... . Media are spaces of action for constructed attempts to connect what is separated» (Zielinski 2006, 7).

Los libros móviles, también denominados a partir de un determinado momento pop-up o desplegables, conforman un punto de inflexión en la trayectoria del libro como soporte de ficción, hacia otras experiencias que van más allá de la tradicional lectura de texto e imágenes. Esta experiencia integra narración escrita, la trasformación de la ilustración en imagen animada y tridimensional, lo que da lugar a la visualización de un espacio explorable y por supuesto los atisbos de la interacción. El lector se posiciona en un nuevo lugar en el que se le invita a la coparticipación de la historia narrada. Esta función de los libros móviles se inscribe en una doble direccionalidad de las influencias de los espectáculos de entretenimiento del siglo XVIII y XIX, que como si fueran llevados por un constante movimiento centrípeto y centrífugo, tienden a concentrar en un solo soporte las innovaciones surgidas de forma separada y, a su vez, el medio que sirve de crisol vuelve a engendrar, bajo el fruto de la experiencia aglutinada, un movimiento de expansión e influencia en futuros medios.

Esta doble dirección se nos antoja mucho más esclarecedora para entender la genealogía de determinados medios que la pura semejanza y cronología formal y material. El proceso que alumbra los libros móviles es similar al seguido por el nacimiento y la evolución de los videojuegos. Mantiene las mismas pautas de concentración en un nuevo soporte y llega a soluciones formales similares, aunque con tecnologías diferentes, porque ambos responden a un ideal de ficción que ha sido seminal en la gestación del entretenimiento de Ios dos últimos siglos: la utopía de la inmersión absoluta y del control del mundo ficcional. Esta utopía ya es perceptible en el espíritu que inspira la ingente obra del jesuita Athanasius Kircher, en el siglo xvIl, en sus escritos y especialmente en sus invenciones e ingenios ópticos. El interés de los jesuitas por la imagen nace de la concepción del fundador de la orden, Ignacio de Loyola, de las visiones interiores como un espectáculo donde se representan los pasos para el camino de la perfección, que no es otro que el vínculo con el más allá. Un proceso de purificación y catarsis mediante la inmersión en las visiones imaginadas primero, contempladas mediante la puesta en escena de los artefactos ópticos después (Mayrata 2017). Libros móviles y videojuegos surgen como frutos de un árbol que, aunque distanciados en el tiempo y en distintas ramas, son únicos pero a la vez similares porque por ellos corre la misma savia, esa marca genética.

\section{El espectáculo entre las manos: nacimiento del libro móvil}

La investigación en torno al libro móvil es relativamente reciente comparada con la que se ha prestado no solo a los orígenes de los medios de comunicación, sino también a otros géneros y formatos de la literatura infantil. Quizás ahí resida buena parte de su olvido; el libro móvil se considera, primero, un género destinado al público infantil, y segundo, su contenido se adscribe a la literatura para niños en un orden inferior del que se sitúan las grandes narraciones. Ha sido a partir de su resurgimiento en los años ochenta del pasado siglo cuando ha merecido una nueva atención gracias a la labor de diseñadores que han impulsado el libro móvil y el pop-up adaptando narraciones tradicionales, mundos ficcionales de cine y series de televisión y, sobre todo, por los trabajos más cercanos a propuestas artísticas en el formato conocido como libro álbum. El libro álbum se dirige a todo tipo de públicos, con piezas algunas de ellas casi sin texto, donde la plasticidad de la construcción animada o tridimensional está a medio camino entre el diseño de vanguardia o nuevos formatos como la novela gráfica.

Aun así, el libro móvil se sigue inscribiendo en un territorio indefinido entre los recortables, el libro de diseño y la literatura infantil. Pocos son los autores que han visto conexiones entre los libros móviles y los espectáculos coetáneos a su nacimiento o como antecesores del audiovisual: Eric Faden (2007) considera a los libros móviles antecesores del cinematógrafo; John Plunkett (2007) los 


\section{artnodes}

relaciona con los espectáculos basados en dispositivos ópticos; y Jacqueline Reid-Walsh $(2006,2007)$ descubre las adaptaciones de las pantomimas teatrales en las arlequinadas. Las influencias no se perciben en los videojuegos, quizás por su lejanía temporal y por el carácter eminentemente tecnológico de estos últimos, lo que parece descartar de antemano cualquier tipo de nexo con soportes de papel.

A lo largo de los siglos XVII y XIX se sucedieron una serie de espectáculos populares que se han mostrado históricamente como hitos sucesivos y conectados, bien sea por su raíz tecnológica, por el efecto visual en el que se basan o por su estructura de espectáculo público, como precursores del cine y del resto de medios audiovisuales. Sin embargo, resulta más esclarecedor que apoyarse en un determinismo tecnológico revelar las características de la cultura digital que no son nuevas, sino que nos remiten a procesos previos (Elsaesser 2016), mediante los que se fue construyendo un concepto de la mirada, de la privacidad y del control, visiones que influirán sobremanera no solo en la génesis y evolución de los espectáculos y artefactos ópticos, sino también, y lo que resulta más importante, en la relación que se establece entre el público y los mundos de ficción que se representan. Kara Marie Manning (2016) revela cómo las obras de Dickens, Brontë, Lewis Carroll o Arthur Conan Doyle integran en sus escenas una manera de ver y representar los efectos cinemáticos que conectan con los estilos de representación de los espectáculos coetáneos: fantasmagorías, peep shows, dioramas, panoramas, espectáculos de linterna mágica, de autómatas, marionetas, estereoscopia, etc. De esta forma, para la autora, ciertas novelas británicas se convierten en proto-cinemáticas, en el sentido de que anticipan la representación visual cinematográfica.

Detrás de este estilo visual literario y de los espectáculos populares de fuerte contenido visual apoyado en ilusiones ópticas, está el interés decimonónico por la imagen como captura de la vida y su cosificación, en el sentido de posesión mediante una representación objetual que, además, se convierte en signo de prestigio social. La popularización de la fotografía, tanto para el retrato personal como para el disfrute de vistas postales y estereoscópicas de lugares remotos, se convierte en una forma de poseer el mundo a través de objetos que se disfrutan en el hogar. El hogar burgués introduce el mundo en su espacio mediante tecnologías y objetos que los representa, así como domestica los espectáculos masivos. En sus salones se desarrollarán obras teatrales, tableaux vivants (pinturas vivientes), juegos de billar y los visionados para la familia y los amigos, o individuales mediante linternas mágicas domésticas, anteojos encantados, zootropos, etc. (Dawson 2013).

Este contexto cultural no podía de dejar de influir en el soporte más revolucionario existente entonces, el libro. Por su naturaleza, el libro se adapta perfectamente a los requerimientos de este proceso de síntesis: fácilmente transformable por su materialidad, con larga tradición en los vínculos de la imagen y la narración y con unas características que lo diferencian del resto de los espectáculos, la intimidad que propicia el disfrute individual y la capacidad de intervenir en el desarrollo de la lectura. Mucho antes de que se hable de libros móviles, ya surgieron formas literarias que adaptaban los personajes y las escenas de la comedia del arte a finales del siglo xvII: las arlequinadas. Más que libros, eran pliegos de hojas que hábilmente dobladas permitían al lector un juego de solapas en las que, sobre un pequeño texto, se ilustraba una escena, por lo general cómica, cuyo resultado se visualizaba levantando una solapa revelando el cambio sobre el dibujo original. Esqueletos que salían de un armario ante la sorpresa de doncellas asustadas 0 arlequines cuya faz cambiaba eran efectos que insinuaban una breve secuencialidad basada en la sorpresa revelada por el descubrimiento de la solapa. Por primera vez, se otorgaba al lector el control de la narración con el sencillo acto de levantar una hoja (Reid-Walsh 2006).

La técnica de la imagen cambiante pasa de la arlequinada al libro de la mano del editor británico Thomas Dean a principios del siglo XIX. Dean crea una serie de libros que incorporan las primeras lengüeteas que, al tirar de ellas, producen el movimiento de los personajes. Había nacido así el libro móvil. La ilustración se despegaba de la base de la hoja para componer un artefacto nuevo con piezas móviles, a partir de figuras recortadas. Esta palabra nos obliga a detenernos en un tipo de juguetes que nace también en aquellos años y que en cierta medida se emparenta con el libro móvil: los recortables. A finales del siglo xvil se popularizan las planchas con figuras recortables de soldados y muñecas como resultado de los avances en la impresión gráfica y de la moda de las siluetas, retratos económicos realizados tomando como base el perfil del sujeto. El recortable permite acostumbrar tanto al ilustrador como al lector a la idea de una imagen manipulable. Ahora bien, el nexo entre unos y otros es fino, ya que el recortable tiende hacia el juguete y el libro móvil está más cercano a la narración y al juego.

El recortable, como el juguete, necesita de una historia o las reglas de un juego. Es lo que aporta la imaginación del niño; sin embargo, el libro móvil no se desvincula del texto como guía de las sucesivas interacciones que se producen en el libro. Es significativo cómo este nexo se evidencia en las series que editó el juguetero Fuller, en Londres (1810), de unas muñecas recortables acompañadas de un libro en el que se narraban las aventuras de las protagonistas. Las niñas jugaban con las muñecas vistiéndolas según fuera necesario por las escenas de la historia, pero era frecuente que pudieran cambiar el sentido obligado del texto jugando con ellas a su propia voluntad (Field 2012). Este uso releva una tensión que es objeto de debate actual en todos los medios interactivos y en los videojuegos: ¿en qué medida el usuario tiene libertad para construir su propia historia? (Jenkins 2004). El libro móvil obliga por su materialidad a una secuencia lineal, a una estructura que no se puede alterar. El recortable se desprende de un soporte y permite un juego y una historia modular. 


\section{artnodes}

\section{La evolución del libro como soporte de experiencia lúdica}

El salto cualitativo más evidente en el libro móvil es el que protagoniza la imagen que va a anticipar efectos cinemáticos, interactivos y a convertirse en un espacio tridimensional explorable. Reflejo de este protagonismo es la nomenclatura con la que se denomina a este tipo de libros y que abunda en la idea de mecánica y efecto visual: mechanical books, toy books, magic books, bookano (acrónimo de Book y Meccano, el popular juego de construcción). Un tipo de nomenclatura que recuerda las que se producen en el nacimiento de los nuevos medios, como los juegos electrónicos, juegos por computadora y finalmente videojuegos.

Las técnicas para llegar a la imagen viviente son variadas. Los primeros efectos se basan en la trasformación, el cambio de una a otra. La primera es la conocida como como persiana veneciana. Una imagen se compone de varias láminas en franjas horizontales, verticales 0 en espiral, que al tirar de una lengüeta se deslizan y se ocultan revelando otra imagen.

También era posible crear movimiento mediante el giro de un disco que accionaba el lector y que permitía el cambio de imágenes vistas a través de una ventana.

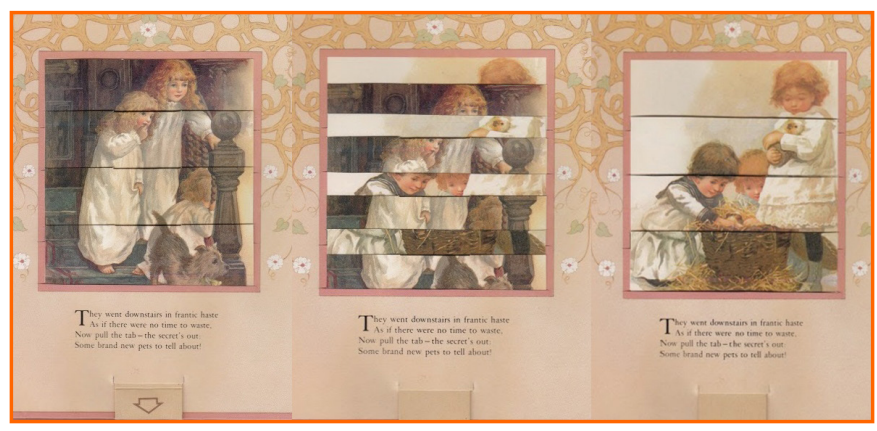

Imagen 1. Efecto de cambio de imagen mediante láminas. Nister (1901). Playtame Surprise https://pigtailsinpaint.org/tag/childrens-book-art/

Para crear efectos de movimiento, el libro necesitaba incorporar un tipo de tecnología que a partir de ahora se sumara a la labor de redacción del texto y el diseño de la ilustración: la ingeniería de papel. Mediante complejas estructuras mecánicas realizadas con cartón, remaches de latón, hilos, anillos de caucho o incluso alambres que permanecen ocultos entre dobles páginas, se consiguen efectos de animación que recuerdan a los sencillos movimientos de los autómatas o las marionetas. Sin duda, uno de los pioneros en la ingeniería de papel es el alemán Lothar Meggendorfer (1847-1925), cuya extensa carrera dejó numerosas piezas de ingeniería de figuras articuladas, así como de excelentes panoramas desplegables.

Los personajes creados por Meggendorfer iban más allá de simples movimientos oscilatorios al tirar de la lengüeta, llegando a construir personajes con complejas articulaciones que permitían, por ejemplo, emular el juego de billar o la interpretación de un violinista.

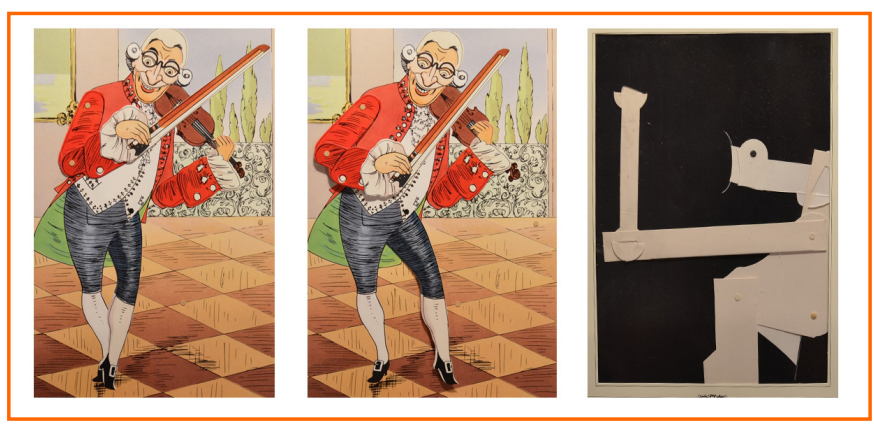

Imagen 2. Animación de la figura mediante ingeniería de papel (detalle a la derecha) (1985). The genius of Lothar Meggendorfer. Fotografía del autor.

Estos efectos de cambio de imágenes y de animaciones seguían siendo bidimensionales, lo que hacía que se mantuviera el punto de vista de observación habitual: el libro en posición vertical frente al lector. Pero un nuevo impulso en la ingeniería de papel va a cambiar la relación habitual del punto de vista y la forma de contemplación del libro.

Las escenas tridimensionales van a permitir, en sus diversas formas, que el libro se convierta en espacio cuyo punto de vista cambie a medida que se gire en cualquier dirección o posición. Estableciendo un paralelismo con la evolución del juego digital y su representación del espacio, podríamos decir que el primitivismo de los primeros juegos arcade se basa en un punto de vista fijo sobre un espacio global donde la cámara no se mueve y en el que se desarrollan las acciones de los personajes con movimientos laterales que recuerdan a los de los actores en un escenario (movimientos formados por loops o ciclos). El espacio bidimensional articulará la mayor parte de los videojuegos durante más de una década, hasta que la evolución gráfica y de potencia de procesamiento permita la visualización de un espacio tridimensional en tiempo real. La cámara responde al cambio de punto de vista que se produce por el movimiento del personaje controlado por el jugador, que puede moverse con total libertad por el mundo digital, lo que fomenta la sensación de control y las dinámicas de exploración.

La técnica que va a permitir superar la bidimensionalidad en los libros va a suponer un cambio para el lector similar al citado en el jugador de videojuegos cien años después. Las primeras escenas tridimensionales se articulan sobre la base de la sencilla técnica de emular la profundidad teatral creando varios términos que se construyen al pasar página. Si al lector se le pedía que realizara una sencilla interacción para animar las figuras, ahora se le ofrece la posibilidad de la exploración libre mediante la mirada. Y para ello deberá girar el libro, acercarse, alejarse, etc. 


\section{artnodes}

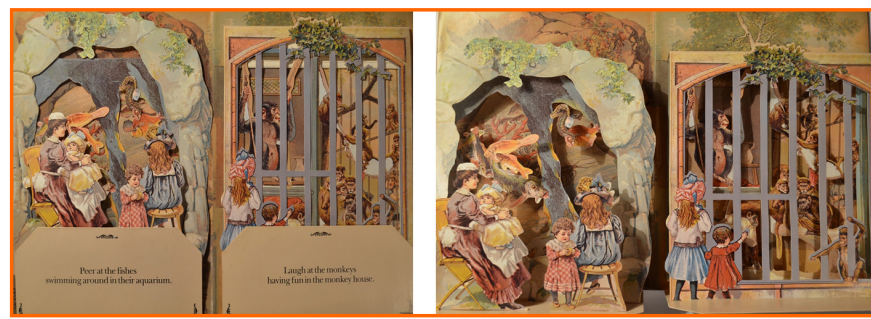

Imagen 3. Efecto de profundidad (1980). A day in the Zoo. Reproducción. Fotografía del autor

El libro móvil recoge aquí la larga experiencia de otro espectáculo popular que se centra en la observación de escenas: el peep show. Bien sea en instalaciones fijas o en cajones ambulantes, el peep show ofrecía el visionado de una escena en la que se hacía hincapié en los efectos de profundidad a partir de descomponer una imagen, generalmente un paisaje, en varios términos. A ello se le añadían otros efectos, como cambios de luz, que mostraban el paso del día a la noche (Huhtamo 2008).

El predominio de la mirada libre gracias a la tridimensionalidad se potencia de varias formas. Primero, cuando la escena tridimensional se separa del juego teatral de la doble página para crear en el centro de esta una figura o escena corpórea. Nace así el verdadero pop-up 0 desplegable. Estas escenas llevan a su máximo nivel de complejidad la ingeniería de papel cuando, al abrir la página, se alzan unas figuras que parecen emerger del libro. La escena deberá ser contemplada en todos sus ángulos, rotando e inclinando el libro. En términos visuales, hemos pasado de la cámara fija a la cámara móvil.

En segundo lugar, el diseño va más allá y el libro se adapta a nuevas estructuras que rompen el juego de la doble página para articularse como un carrusel de escenas tridimensionales, 0 incluso se convierten en un verdadero peep show modular cuando las hojas troqueladas permiten la visión de varios términos.

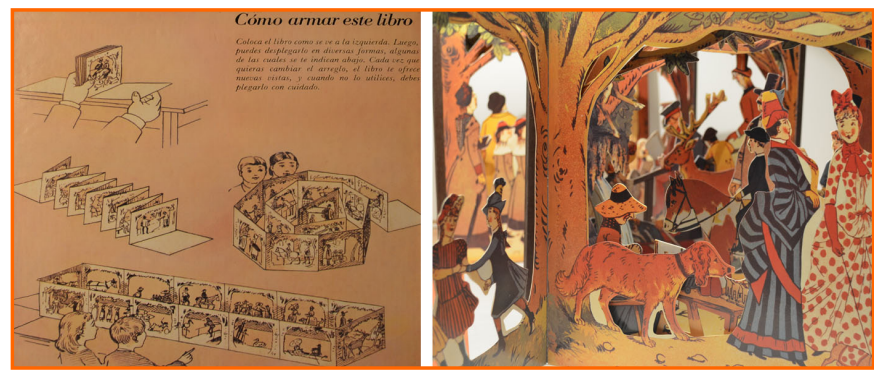

Imagen 4. Emulación de peep show. Lothar Meggendorfer (1981). El parque urbano. Reproducción. Fotografía del autor.

Esta ruptura del formato tradicional del libro llega a su máxima expresión cuando se convierte en un panorama que emula la disposición de un espacio, como sucede en el caso de una de las mejores obras de Meggendorfer, el Circo Internacional. El diseño permite desplegar un circo con efecto tridimensional y poder abrirlo o cerrarlo hasta crear el espacio circular de la pista y las gradas.

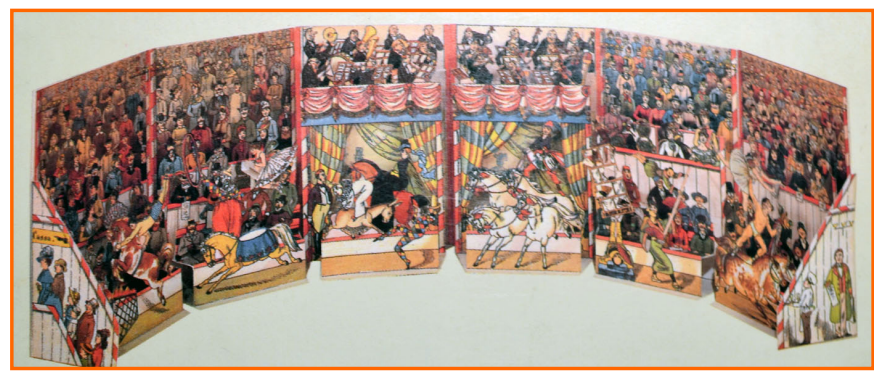

Imagen 5. Lothar Meggendorfer (1981). Circo Internacional. Reproducción. Fotografía del autor.

A las escenas tridimensionales que se despliegan en el centro de las hojas, la ingeniería de papel incorpora nuevos efectos de movimiento. Es frecuente que al desplegarse la escena aparezca algún dispositivo móvil, sujeto a una cuerda o tira que haga que un personaje se mueva por sí solo.

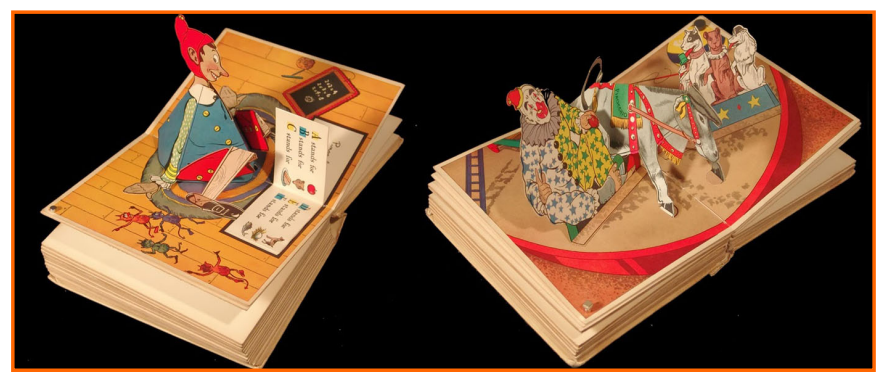

Imagen 6. Escenas tridimensionales. Lentz (1932). Pinocchio, Blue Ribbon Books. http:// javiercoria.blogspot.com.es/2014/03/the-pop-up-pinocchio.html

Las innovaciones en la imagen del libro móvil no van a dejar indiferente al hasta ahora componente esencial del libro: el texto. Las relaciones entre texto e imagen han sido establecidas en función de la complementariedad, la subordinación explicativa de texto frente a imagen o viceversa, e incluso de la creación de lagunas textuales que cubren la imagen. Todos los autores que han investigado estas relaciones coinciden, desde diversas aproximaciones, en que la compresión total de la historia no radica exclusivamente en el texto 0 en las imágenes, sino en el producto de su mutua relación (Martinec 2005; Sánchez García 2005). El libro móvil parte de esta herencia, pero replantea la relación orientándola hacia otro estatus, donde el texto se complementa con una experiencia táctil e interactiva que antes no proporcionaba la imagen. La ilustración tradicional requería de un tipo de mirada y actitud en el lector distinta. Podía ser tan compleja como las pinturas históricas, con varios términos en la representación de una batalla, que obligaban a una mirada 


\section{artnodes}

Ienta y minuciosa con el fin de buscar detalles que permitían extraer una lectura narrativa. Sin embargo, la imagen viviente del libro móvil se simplifica supeditándose al efecto animado 0 a la sorpresa. Un efecto que entronca con la estética del asombro que tanto va impregnar el resto de espectáculos y medios posteriores (Gunning 1986). Es más sencilla porque está diseñada para otro efecto que va más allá de la contemplación, el movimiento o la construcción espacial. El texto también se simplifica anticipando el efecto de animación, en algunos casos, o sirviendo a otro fin: en algunos párrafos, el libro se dirige al lector y le instruye sobre cómo debe manipularlo, colocándose de esta forma en un territorio distinto al de la ficción. Las partes manipulables junto con los textos explicativos, nos permiten aventurar la noción de lo que será más tarde el interfaz, ese espacio intermedio entre el usuario y la ficción y que sirve de sistema de control.

Se puede constatar, a lo largo de los años, una tendencia a que la arquitectura de papel del libro móvil vaya arrinconando al texto, de forma que su presencia se minimice o bien se dramatice dentro de las posibilidades de interacción del libro. Este proceso es patente en una técnica conocida como encartes. Son piezas que se incluyen dentro del libro y que se pueden sacar para manipularlas de forma independiente. Suelen ser pequeñas cartas, objetos, tarjetas, etc. que incorporan textos o dibujos que aportan información sobre la historia. La información textual se adapta a la propia escena y se predispone al lector a un ejercicio de exploración muy similar al que se produce en los videojuegos de aventura gráfica, donde la manipulación de objetos es frecuente para poder construir el sentido de un puzle, un enigma o la historia global.

\section{Conclusión}

Si buceamos en el tiempo profundo (Zielinski 2006), nos encontraremos con conexiones insospechadas pero constantes entre diferentes medios aparentemente lejanos. La tensión por reunir en un soporte sencillo, manejable y dúctil los hallazgos espectaculares que se vienen fraguando desde el siglo xVIII constituye una corriente que asoma en diversos momentos con características sociales similares. Cada tiempo toma los soportes y las tecnologías que tiene a su alcance, dando origen a fecundos artefactos que marcan el ocio durante décadas. El libro, el mejor soporte de la cultura occidental para la difusión del conocimiento, no puede dejar de relacionarse con el otro mejor soporte: el digital. Las conexiones entre libros móviles y videojuegos como emergencias de las utopías lúdicas permanecen vigentes si atendemos a esa doble dirección que señalábamos al comienzo del trabajo: la fuerza centrífuga-centrípeta. Los videojuegos han devuelto ahora sus técnicas a nuevos formatos literarios digitales, como el game book o la ficción interactiva, y si vamos más allá también lo han hecho a los espectáculos y atracciones que sirvieron de caldo de cultivo de libros móviles. En los últimos años, es frecuente la utilización de imágenes de realidad virtual e interacción en los interactive rides de grandes atracciones en parques temáticos. El bucle permanece en constante flujo.

\section{Referencias bibliográficas}

Bolter, J. and R. Grusin. 1998. Remediation: Understanding New Media. Cambridge: MIT Press.

Dawson, M. 2013. Laboring to Play: Home Entertainment and the Spectacle of Middle-Class Cultural Life, 1850-1920. Tuscaloosa: The University of Alabama Press.

Elsaesser, T. 2016. Film History as Media Archaeology. Tracking Digital Cinema. Amsterdam: Amsterdam University Press.

Faden, E. 2007. «Movables, Movies, Mobility: Nineteenth-century looking and reading». Early Popular Visual Culture, vol. 5, $\mathrm{n}^{0} 1$ : 71-89. https://doi.org/10.1080/17460650701269820

Field, H. 2012. «A story, exemplified in a series of figures: paper doll versus moral tale in the nineteenth century». Girlhood Studies, vol 5, no 1: 37-56. https://doi.org/10.3167/ghs.2012.050104

Gunning, T. 1986. «The Cinema of Attractions: Early Film, Its Spectator, and the Avand-Garde». Wide Angle, vol. 8, n. ${ }^{0}$ 3-4: 63-70.

Huhtamo, E. 2008. «The Pleasures of the Peephole:An Archaeological Exploration of Peep Media». En E. Kluitenberg (ed.). Book of imaginary media: excavating the dream of the ultimate communication medium. Amsterdam: Nai Publishers.

Huhtamo, E. 2007. «Máquinas de diversión, máquinas de problemas». En «Jugabilidad: arte, videojuegos y cultura». Artnodes. N. ${ }^{\circ} 7$ : 43-60.

Jenkins, H. 2004. «Game Design as Narrative Architecture». En N. Wardrip-Fruin and P. Harrigan (eds.). First Person: New Media as Story, Performance, and Game. Cambridge: MIT Press.

Manning, K. M. 2016. Moving Words/Motion Pictures: Proto-Cinematic Narrative In Nineteenth-Century British Fiction. Tesis, Graduate School and the Department of English. The University of Southern Mississippi.

Martinec, R. 2005. «A system for image-text relations in new (and old) media», Visual Communication, vol. 4, $n^{0}$ 3: 339-374.

Mayrata, R. 2017. Fantasmagoría. Magia, terror, mito y ciencia. Madrid: La Felguera.

Plunkett, J. (2007). «Moving Books/Moving Images: Optical Recreations and Children's Publishing 1800-1900». 19: Interdisciplinary Studies in the Long Nineteenth Century, № 5. https://doi. org/10.16995/ntn.463

Reid-Walsh, J. 2007. «18th Century Flap Books for Children: Allegorical Metamorphosis and Spectacular Transformation». Movable Stationery, vol. 14, n² 2. https://doi.org/10.1111/j.1754-0208.2006. tb00657.x 


\section{artnodes}

http://artnodes.uoc.edu

Arqueología de la interactividad...

Reid-Walsh, J. 2006. «Pantomime, Harlequinades and Children in Late Eighteenth-Century Britain: Playing in the Text». Journal for Eighteenth-Century Studies, vol. 29, $\mathrm{n}^{0}$ 3: 413-425. https://doi. org/10.1111/j.1754-0208.2006.tb00657.x
Sánchez García, R. 2005. «Morfología del texto y producción de sentido en la lectura». Ayer, n 58: 57-86.

Zielinski, S. 2006. Deep Time of the Media. Toward an Archaeology of Hearing and Seeing by Technical Means. Cambridge: The MIT Press.

\section{CV}

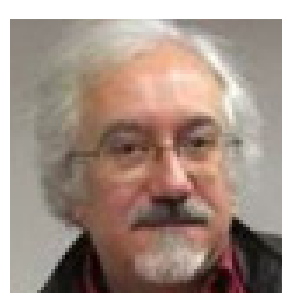

Alfonso Cuadrado Alvarado

Departamento de Ciencias de la Comunicación y Sociología

alfonso.cuadrado@urjc.es

Facultad CC. Comunicación

Universidad Rey Juan Carlos

Camino del Molino, $\mathrm{s} / \mathrm{n}$.

2894 Campus de Fuenlabrada (Madrid)

Alfonso Cuadrado es profesor en la Universidad Rey Juan Carlos. Doctor en el año 2007 por la Universidad Complutense con la tesis «Los personajes virtuales en el videojuego Los Sims 2». En el grado de Comunicación audiovisual imparte las asignaturas Narración audiovisual, Guion audiovisual e Imagen sintética y videojuegos. Participa en el diseño del plan de estudios del grado en Diseño y desarrollo de videojuegos en el que actualmente imparte las asignaturas Narración, guion y storyboard y Fundamentos del diseño y la jugabilidad. Es autor de más de una veintena de artículos, de varios capítulos de libro y del manual Narración audiovisual. Sus líneas de investigación se centran en las influencias e interdependencias en la narración y estética del cine, las series televisas y los videojuegos. 